\title{
Audit of the quality of consent form completion and improvement of practice
}

This article was published in the following Dove Press journal:

Clinical Audit

12 September 2012

Number of times this article has been viewed

\author{
Stavros Constantinou \\ Panagiotis A Dimitriadis \\ Department of General Surgery, \\ Royal Berkshire Hospital, Reading, \\ Berkshire, UK
}

\begin{abstract}
To achieve excellence in clinical practice and a high level of health care provision, consent processes need to be clear and precise. In particular, patients who are to undergo elective operations must be fully informed before consenting to treatment. The aim of this study is to assess the quality of consent form completion by different health professionals in our department and to identify areas for potential improvement. We audited 35 elective laparoscopic cholecystectomy consent forms, using a set proforma to produce a final score for each form, in order to assess the quality of consent completion and to recommend changes. We then implemented these changes in our current clinical practice and subsequently re-audited our performance. Our results suggest that targeted, specific, and low cost interventions could significantly improve consent processes. This will considerably improve the quality of health care provision and better protect the surgeons/trust in medico-legal cases.
\end{abstract}

Keywords: audit, consent, cholecystectomy

\section{Introduction}

To achieve excellence in clinical practice and a high level of health care provision, patient consent processes for medical treatments need to be clear and precise. In particular, patients who are to undergo elective operations must be fully informed before consenting to treatment. The importance of the consenting process is clearly highlighted in the General Medical Council's guidelines for doctors, entitled, Consent: patients and doctors making decisions together. ${ }^{1}$ The effectiveness of the consenting process almost always reflects the quality of completion of the consent forms. In addition, incomplete information on consent forms may leave clinicians and the trust liable to medico-legal actions if things go wrong. The aim of this study is to assess the quality of consent form completion by different health professionals in our department and to identify potential areas for improvement.

\section{Methods}

We audited 35 elective laparoscopic cholecystectomy consent forms in order to assess the quality of consent completion. We included all patients who had attended our department for an elective laparoscopic cholecystectomy within a 1.5 month period (January-February 2012). All patients had the capacity to consent (Consent form 1). All operations were assessed for completion of all relevant areas and were analyzed using a set proforma in order to produce a final score for each form (maximum score 10/10).
Correspondence: Panagiotis Dimitriadis 6 Theobald Crescent, HA3 5NB, Harrow, Greater London, UK

Tel +4475 40374330

Email panagiotis.dimitriadis.09@ucl.ac.uk submit your manuscript $\mid$ www. dovepress.com

Dovepress

http://dx.doi.org/10.2147/CA.S34734 
Points were allocated as follows:

Page 1 of the consent form: Patient's details (1), responsible health professional and job title (1),

Page 2 of the consent form: Benefits (1), complications (1), operation (including any procedures needed) (1),

Page 3 of the consent form: Name (1), signature (1), date (1).

We also scored legibility of the writing used on the consent form, as follows: easily readable (2), needs one more colleague to read it (1), no one can read it (0).

For in-depth analysis of the laparoscopic cholecystectomy consent forms, we used the set categories for benefits and risks that should be documented according to the National Health System (NHS) direct website ${ }^{2}$ and a literature review on PubMed. ${ }^{3,4}$ We then analyzed the scoring according to three different categories, depending on the level of seniority of the consenting clinician (consultant, surgical registrar, or senior house officer). Relevant risks found essential for documentation were: bleeding, infection, vascular/visceral injury, conversion to open procedure, bile leak, common bile duct injury, retained stones, pulmonary embolus/deep vein thrombosis, and death (0.1 point was deducted for each risk that was not included).

The average scoring, subdivided to the previous categories was as follows: consultants, 7/10; surgical registrars, 7.6/10; and senior house officers, 8/10 (Figure 1). Identification of the responsible consultant, documentation of complications, and illegibility were the top three categories where the health professionals lost points. The results clearly show that significant improvement is needed in the quality of completion of consent forms.

The interventions that we suggested and subsequently implemented were the following: All of the surgical wards and the pre-assessment unit were provided with stickers indicating the benefits and complications of laparoscopic cholecystectomy. These stickers were applied to the consent forms. The medical benefits and complications of the laparoscopic cholecystectomy procedure were uploaded onto the hospital's intranet homepage. All consenting professionals

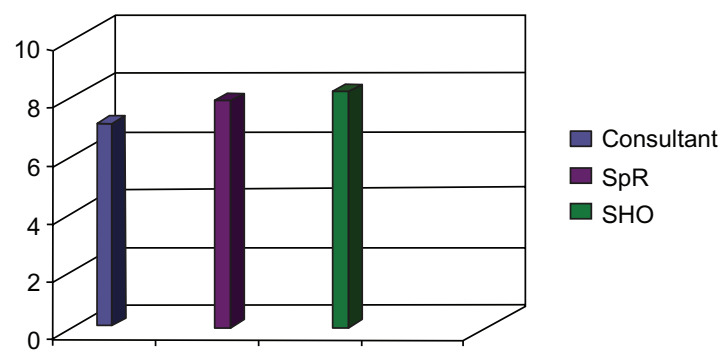

Figure I Average scoring per health professional, before our intervention. involved were educated in local teaching sessions about the importance of full completion of consent forms; surgical registrars led the process. Leaflets were printed and given to patients in the outpatient clinic to inform about the procedure, benefits, and risks of laparoscopic cholecystectomy so that they were informed in advance.

\section{Results}

At the reaudit, we collected the consent forms from the first 35 patients that attended our department after we had implemented our interventions (May-June 2012). The reaudit data analysis showed the following average scores: consultants, 9.2/10; surgical registrars, 9.7/10; and senior house officers, 10/10 (Figure 2).

At the reaudit, all consent forms used the stickers that had been provided to the pre-assessment unit and surgical wards. As a result, what remained for the doctors to write by hand were their names, grades, and the date; consequently, illegibility was no longer an issue.

\section{Discussion}

The process of obtaining informed consent is crucial in the daily life of surgeons. Accuracy in consent practice as well as in consent documentation are of paramount importance; the surgeon should be able to explain the procedure, its benefits and complications, and other treatment options in lay terms so that the patient can understand, weigh information, and make an informed decision. Some trusts in the UK have introduced consenting clinics, where the surgeons discuss the operation with the patients at the clinic and provide leaflets for the patients to take with them. The actual signing of the consent form then occurs on the day of the operation. However, not all departments (including ours) run consenting clinics. In these cases, the consenting doctor should have a good knowledge of the procedure and must document clearly what is discussed with the patient.

Illegibility becomes a critical issue, especially in terms of litigation. In our study, a form that needed more than one

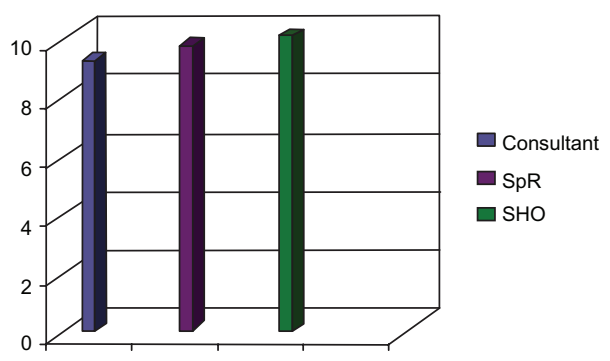

Figure 2 Average scoring per health professional, after our intervention. 
person to read it would get 1 point according to our scoring system, whereas if no one could read it, it scored 0 ; ie, one could argue that illegibility is "all or nothing." However some people may be more familiar with different types of handwriting than are others. The use of stickers reduced what was needed to be handwritten to the minimum.

This type of sticker use, together with investments in education and awareness, are known to improve "bestpractice" within a health system. It will be interesting to see whether the improvement in behavior observed in the present case will be sustained over the long term; continuous reauditing of the practice is necessary.

\section{Conclusion}

Our results suggest that targeted, specific, and low cost interventions can significantly improve consent processes. These improvements will considerably enhance the quality of health care provision and the surgeons/trust will be better protected in medico-legal cases. In addition, training will noticeably improve, as junior doctors will benefit from a standardized and accurate consent process.

A step forward to improve the consenting process nationally would be to create a surgical consent form website that would combine the information leaflet and procedure details with the consent form itself (with separate forms for each different procedure). This would eliminate illegibility issues and would also provide a common source for patient information and for discussions with the health care professionals involved in obtaining consent.

\section{Disclosure}

The authors report no conflicts of interest in this work.

\section{References}

1. GMC.org [homepage on the Internet]. London, UK: General Medical Council. Available from: http://www.gmc-uk.org/guidance/ethical_guidance/consent_guidance_index.asp, updates June 2, 2008. Last accessed September 5, 2012.

2. NHS.uk [homepage on the Internet]. City, UK: National Health Services. Available from : http://www.nhs.uk/Conditions/Laparoscopiccholecystectomy/Pages/Riskspage.aspx [Updated September 2, 2012]. Accessed September 5, 2012.

3. Fletcher DR, Hobbs MS, Tan P, et al. Complications of cholecystectomy: risks of the laparoscopic approach and protective effects of operative cholangiography: a population-based study. Ann Surg. 1999;229(4):449-457.

4. Shamiyeh A, Wayand W. Laparoscopic cholecystectomy: early and late complications and their treatment. Langenbecks Arch Surg. 2004;389(3): 164-171.
Clinical Audit

\section{Publish your work in this journal}

Clinical Audit is an international, peer-reviewed, open access journal focusing on the processes and outcomes of clinical audit in any area of healthcare. All aspects of patient care are addressed within the journal and practitioners from all disciplines are invited to submit their work. Areas covered include: Publication of audits; How an audit has changed practice;

\section{Dovepress}

Practical tips on how to do audits and to avoid pitfalls; How audits have changed patient care; Calls and justifications for new audits. The manuscript management system is completely online and includes a very quick and fair peer-review system, which is all easy to use. Visit http://www.dovepress. com/testimonials.php to read real quotes from published authors. 